\title{
ESSENTIALS ISSUES FOR E-GOVERNMENT EFFICIENCY
}

\author{
José Jorge-Pagán, Universidad Ana G. Méndez, jorgej1@uagm.edu \\ Angel M. Ojeda-Castro, Universidad AnaG.Méndez,aojeda5@uagm.edu \\ Juan Valera-Márquez, Universidad Ana G. Méndez, valeraj1@uagm.edu \\ Macedonio Alanís- González, Tecnológico de Monterrey, alanis@itesm.mx
}

\begin{abstract}
The main purpose of this study was to establish a model to measure the relationship of successful factors for egovernment efficiency. Theoretical bases were employed for the hypothesis's formulation. The variables identified were classified as internal and external factors, maturity, strategies, interoperability, and standards as independent factors. The exchange of information was identified as the dependent factor. As part of the methodology, a survey was administered to 87 specialists in information systems and statistics. A multivariate analysis was applied to generate the structural equation model. The results showed that internal and external factors such as organizational, economic, and political influences, legislative, and technical; and private procedures and interagency agreements are not related to the exchange of information. However, when internal and external factors are related with maturity, it generates a positive relationship with the exchange of information. There exists association in the collaboration of two or more agencies, and the potential to increase productivity and efficiency of government operations. The research model explains the existence of three composite relationships where information exchange occurs and that justify the efficiency of e-government. In a scenario where change is a constant, e-government faces the challenge of dealing with the technological trends on which to build the resources to enable the exchange, integration, dissemination, and effective use of multiple data sources.
\end{abstract}

Keywords: Electronic Government Interoperability, Government to Government

\section{INTRODUCTION}

E-government is defined as the use of Internet technology to provide traditional services through a technological platform, to be accessible to all citizens, the private sector and the government itself (Siau \& Long, 2009). The egovernment initiatives are associated with political reforms and organizational changes. They should support and effectively guide the transformation of the public sector in its internal administration, maximize their managerial and operational capacities, and strengthen the relationship with other entities through their information systems (Das \& Patra, 2013).

Historically, the exchange of information between government agencies has promoted agile services and effective use of human and technological resources (Siau \& Long, 2009). Nowadays, governments have the responsibility to bring effective solutions for challenges and obstacles related to the effective implementation of an e-government platform. It must be done in a context of constant economic, political and social changes (Ruhode, 2013). The expectation that the information is provided only once and is used by others in multiple instances, raises the need to establish an environment of cooperation and effective exchange of information between public and private bodies (Gatautis \& Vitkauskaite, 2010). The volatility of government policies makes public sector agencies maintain independent IT systems, even under a common platform for electronic government (Amayah, 2013). This behavior is manifested by the lack of knowledge to integrate technologies, reliance on private corporations that manage these systems, or fiscal constraints that prevent them to invest in new hardware, software and staff to adapt to technological changes (Apostolou et al., 2011; Al-Khanjari et al, 2013).

The implementation of e-government has been studied from different perspectives, from its adoption to its continued use at the organizational level (Zinner \& Rukanova, 2010). To fulfill the expectations and requirements of the e- 


\section{Issues in Information Systems}

Volume 21, Issue 1, pp. 98-104, 2020

government platform adopted, it should facilitate the collection of information and access. Furthermore, it should guarantee its security, availability, and standardization in the exchange (Fan et al, 2014).

Most of the public sector migrate their IT platform and Internet infrastructure management as part of its strategy of technological expansion and get into the concept of electronic government (United Nations, 2012). Despite the efforts of governments, the exchange of information among agencies has not been fully developed and implemented (AlKhanjari et al, 2013). The adoption and diffusion of services under e-government platforms has faced problems due to the lack of development of a country as a technological component (Asogwa, 2013). A challenge for any public administration is the creation of an e-government platform that adapts to changes in legislation, policy, scope, technology, and user needs (Apostolou et al., 2011). The biggest challenges are manifested in the internal structure of e-government (G2G), where interoperability and key services may be affected substantially. This can have a ripple effect on other complementary services of electronic government (Ruhode, 2013; Fan et al, 2014).

The main objective of this research was to identify factors that influence the exchange of government information. Also, it measures how the adoption of information technologies, and the search for interoperability and stability, facilitate the establishment of a single resource dissemination and exchange of information, continuity of operations, and support for management decision making.

\section{LITERATURE REVIEW}

Economic issues are associated with elements that measure the wealth of a country and have an impact on the operation of government agencies (Bigdeli et al, 2013). Some countries try to establish solutions in accordance with their limited financial and technological resources. Governments will remain in a learning cycle based on trial and error, by not having specific studies to help them steer and maximize available resources (Rahman, 2010).

The issue of security in e-government is sensitive because of the effect it can have on public opinion and is often treated confidentially in countries (Al-Khanjari et al, 2014). The benefits that can be obtained through an e-government platform are prone to hazards in its infrastructure, security, management, obsolescence, or sensitivity of the data, among others (Di Natale et al, 2003).

Governments are characterized by conflicts of interest, power struggles, and cultural clashes that modify the viewer's perception of the role of information technology (Cordelia \& Iannacci, 2010). In turn, they increase the complexity of decision making (Boulesnane \& Bouzidi, 2013). Management must identify and promote a culture of support, to transform conflicts of interest, power struggles, and cultural clashes into common goals that help the organization (Amayah, 2013).

Most of the studies on exchange of information in e-government, have focused on the central levels of the organization and their relationship with external entities. These have not been effective from an inter-agency point of view (Bigdeli et al, 2013). The literature review that helps to define the theoretical framework, focuses on the concepts of interoperability, information sharing, maturity, technological and organizational capacity of the government to government component. The establishment of an e-government platform should incorporate cultural, social and economic aspects of the country where its implementation is envisaged, as well as the human resources involved (AlHujran \& Al-Dalahmeh, 2011). However, it has created itself a few limitations that prevent it from reaching the expected level of development (Kawtrakul et al., 2011). Many governments adopt the basic model of e-government as a mechanism to provide immediate results to public pressure but lacks details of its legislation and governmental structure. At last, the final product tends to be underutilized (Córdoba-Pachon, 2009).

The component of government-to-government $(\mathrm{G} 2 \mathrm{G})$ has produced a wide variety of theories and hypotheses that show its potential from the technical, organizational, and cultural perspective (Shrikant, 2012). The G2G systems do not have a common IT infrastructure, resulting in a challenge to achieve optimal communication and collaboration between public organizations at different levels of technological development (Haque \& Memon, 2013). 


\section{Issues in Information Systems}

Volume 21, Issue 1, pp. 98-104, 2020

\section{Internal and External Factors}

There are a variety of barriers to inclusiveness and transparency of information exchange between agencies. The literature agrees on the basic classification of technical, organizational, economic, political, and legislative Governments are complex working spaces (Córdoba \& Orr, 2009) characterized by conflicts of interest, power struggles and cultural clashes that modify the viewer's perception of the role of information technology (Cordelia \& Iannacci, 2010). In turn, they increase the complexity of decision making (Boulesnane \& Bouzidi, 2013). Management must identify and promote a culture of support, to transform conflicts of interest, power struggles and cultural clashes into common goals that help the organization (Amayah, 2013). Other influences are procedures; interagency agreements and legislation carried out in a country (Fan et al, 2014).

\section{Maturity, Interoperability, and Standards}

Interoperability has a high degree of complexity in the relationship between processes (Gottschalk, 2009). To this end, agencies should implement a model of good planning, maturity, active participation of its human resources and effective use of technology (Tripathi et al, 2013). Management style, organizational structure, shared services and collaboration should promote interoperability between organizations (Cheng et al, 2013). Interoperability is defined as the ability of two or more systems or components to exchange and use compatible information (Gottschalk, 2009). They work together using common standards or processes (Gatautis \& Vitkauskaite, 2010) in order to create value (Solli, 2011), and promote their users to work collectively (Headayetullah \& Pradhan, 2010). Interoperability is a wider concept and essentially social-technical (da Silva, 2009), where the relationship between the data and services is an important platform to support electronic government requirements (Tripathi et al, 2013). The efforts that agencies take to achieve high levels of maturity, are absorbed by the challenges of government interoperability (Apostolou et al., 2011).

\section{Information Strategies}

Openness, transparency and accountability are becoming more popular in governments worldwide and are considered unavoidable elements to meet the information needs. (Sandoval \& García, 2011). The resistance of some countries to share information due to their low level of technological expertise, or lack of resources, hinder its effective development in the context of electronic government (Coursey \& Norris, 2008). Management should encourage and strengthen communication between agencies to increase opportunities for development of electronic government (Asogwa, 2013). To achieve this, they should have a strategy to exchange information to make it easy to publish, distribute, and use (Sheridan \& Tennison, 2010).

\section{Government Information Exchange}

The exchange of information is conceived as the collaboration initiatives between two or more agencies that share data across any digital medium, with the potential to increase the productivity and efficiency of government operations (Fan et al, 2014). It also supports the transformation of organizational structures and communication channels of multiple agencies involved in solving public problems (Mendes et al, 2011). This dynamic exchange is modeled by the organizational policy of the agencies involved (Fillotrani \& Estévez, 2010). The exchange of information begins with the release of unclassified information to present an image of transparency and openness of government to the citizen (Flak et al, 2008). This defines the bases of Open Government and promotes the participation and collaboration of other agencies (Jaeger \& Bertot, 2010). Decisions regarding the exchange of information between government agencies fall mostly in senior management. This should influence the adoption of technology, its improvement in performance, and related processes (Fan et al, 2014).

\section{RESEARCH METHODOLOGY}

Our research centered upon the following research question: Do significant factors that affect the exchange of government information (internal and external factors, maturity, interoperability, and strategies).

The research hypotheses to be tested are as follows:

$\mathrm{H}_{1}$ : Maturity of agencies is related positive to $\mathrm{G} 2 \mathrm{G}$ information exchange.

$\mathrm{H}_{2}$ : Interoperability and standards information in agencies are related positive to $\mathrm{G} 2 \mathrm{G}$ information exchange.

$\mathrm{H}_{3}$ : Information strategies used by agencies are related positive to $\mathrm{G} 2 \mathrm{G}$ information exchange.

$\mathrm{H}_{4}$ : The internal and external influences are related positive with maturity. 
$\mathrm{H}_{5}$ : Internal and external influences are related positive with interoperability and standards.

$\mathrm{H}_{6}$ : Internal and external influences are related positive with information strategies.

$\mathrm{H}_{7}$ : Internal and external influences are related positive to $\mathrm{G} 2 \mathrm{G}$ information exchange.

To test these hypotheses, the collection and analysis of data was conducted primarily through a questionnaire distributed to employees of IT and Statistics offices of Puerto Rico government agencies. The research methodology was based on the quantitative multivariate analysis and structural equations. The software of SPSS was used to determine the descriptive statistics, the validity, and reliability of the questionnaire instrument. In addition, the multivariate statistical technique was applied through the PLS-SEM software.

The survey measured employee perceptions about preparing an agency for information sharing, interoperability in three dimensions (technical, organizational, and semantic), maturity in two dimensions (technological and organizational) standards, strategies, and information security, as well as internal and external factors. The constructs were measured in Likert scale with values of 1 to 5 , being "1" the representative of 'never', and 5 the representative of 'Always'. It included questions at the end of the questionnaire that helped obtain a demographic profile of the respondents (gender, academic background, employment status and time working in government).

\section{RESULTS}

The sample consists of 87 people, of which $62 \%$ are men ( 54 responses), and $38 \%$ are ladies ( 33 responses). According to Table 1 , the reliability analysis of the instrument showed an overall value of 0.855 , which shows that the instrument has internal reliability. Kaiser-Meyer-Ohlin test (KMO), which measures the adequacy of the sample and the correlation matrix, and Bartlett's test of sphericity, was also considered. The tests showed values above 0.5 for the KMO test, which validates the adequacy of the sample for this study. Similarly, the sphericity test showed values of $0.000(\mathrm{p}<0.05)$, so that the samples are statistically significant. A Factor Analysis performed shows clearly that just 19 variables produce $78.9 \%$ of the variance. This fact is highly significant given that simplifies the analysis of model (Table 2). This subset of variables is producing so much variability in the response than all other variables jointly. Similarly, 67 variables represent a reliability of 0.855 being a model highly reliable.

Table 1. KMO \& Bartlett

\begin{tabular}{|c|c|}
\hline Proof & Results \\
\hline Reliability & 67 variables: 0.855 \\
\hline Factor Analysis & $\begin{array}{c}19 \text { variables explained } 78.9 \% \text { of the } \\
\text { variance }\end{array}$ \\
\hline KMO \& Bartlett & 0.562 \\
\hline
\end{tabular}

Then, the total variance was calculated. The first 19 variables had higher values of one, representing $78.9 \%$ of the total variance. The first factor explains $21.6 \%$ of the total variance.

Figure 1 below show the results of the p-values, which measured the relationship of each of the assumptions made by the investigator. Evidence of relationship (p-value <.10) in $\mathrm{H}_{1}, \mathrm{H}_{4}, \mathrm{H}_{5}, \mathrm{H}_{6}$, was found relationships; $\mathrm{H}_{2}, \mathrm{H}_{3}$ and $\mathrm{H}_{5}$ of internal and external, Interoperability and Standards, Information Strategies to the Exchange of Information; which was not found relationship factors. 
Issues in Information Systems

Volume 21, Issue 1, pp. 98-104, 2020

Table 2. Total Variance Explained

\begin{tabular}{|c|c|c|c|c|c|c|c|c|c|}
\hline \multicolumn{10}{|c|}{ Total Variance Explained } \\
\hline \multirow[b]{2}{*}{ Component } & \multicolumn{3}{|c|}{ Initial Eigenvalues } & \multicolumn{3}{|c|}{ Extraction Sums of Squared Loadings } & \multicolumn{3}{|c|}{ Rotation Sums of Squared Loadings } \\
\hline & Total & $\%$ of Variance & Cumulative \% & Total & $\%$ of Variance & Cumulative \% & Total & $\%$ of Variance & Cumulative \% \\
\hline 1 & 15.418 & 22.673 & 22.673 & 15.418 & 22.673 & 22.673 & 6.748 & 9.924 & 9.924 \\
\hline 2 & 6.124 & 9.006 & 31.680 & 6.124 & 9.006 & 31.680 & 5.216 & 7.671 & 17.595 \\
\hline 3 & 4.035 & 5.934 & 37.613 & 4.035 & 5.934 & 37.613 & 4.370 & 6.427 & 24.022 \\
\hline 4 & 3.475 & 5.111 & 42.724 & 3.475 & 5.111 & 42.724 & 3.464 & 5.095 & 29.117 \\
\hline 5 & 2.563 & 3.769 & 46.494 & 2.563 & 3.769 & 46.494 & 3.198 & 4.703 & 33.820 \\
\hline 6 & 2.473 & 3.637 & 50.130 & 2.473 & 3.637 & 50.130 & 2.936 & 4.317 & 38.137 \\
\hline 7 & 2.202 & 3.239 & 53.369 & 2.202 & 3.239 & 53.369 & 2.752 & 4.047 & 42.184 \\
\hline 8 & 2.095 & 3.081 & 56.450 & 2.095 & 3.081 & 56.450 & 2.612 & 3.842 & 46.026 \\
\hline 9 & 1.930 & 2.838 & 59.288 & 1.930 & 2.838 & 59.288 & 2.595 & 3.816 & 49.842 \\
\hline 10 & 1.862 & 2.739 & 62.027 & 1.862 & 2.739 & 62.027 & 2.347 & 3.451 & 53.293 \\
\hline 11 & 1.663 & 2.445 & 64.472 & 1.663 & 2.445 & 64.472 & 2.194 & 3.227 & 56.521 \\
\hline 12 & 1.559 & 2.292 & 66.765 & 1.559 & 2.292 & 66.765 & 2.168 & 3.188 & 59.708 \\
\hline 13 & 1.314 & 1.933 & 68.698 & 1.314 & 1.933 & 68.698 & 2.102 & 3.091 & 62.799 \\
\hline 14 & 1.304 & 1.918 & 70.616 & 1.304 & 1.918 & 70.616 & 2.017 & 2.966 & 65.765 \\
\hline 15 & 1.240 & 1.823 & 72.439 & 1.240 & 1.823 & 72.439 & 1.983 & 2.916 & 68.681 \\
\hline 16 & 1.180 & 1.736 & 74.174 & 1.180 & 1.736 & 74.174 & 1.894 & 2.785 & 71.466 \\
\hline 17 & 1.153 & 1.695 & 75.869 & 1.153 & 1.695 & 75.869 & 1.846 & 2.714 & 74.180 \\
\hline 18 & 1.060 & 1.559 & 77.428 & 1.060 & 1.559 & 77.428 & 1.658 & 2.438 & 76.619 \\
\hline 19 & 1.020 & 1.500 & 78.928 & 1.020 & 1.500 & 78.928 & 1.571 & 2.310 & 78.928 \\
\hline 20 & .996 & 1.465 & 80.394 & & & & & & \\
\hline
\end{tabular}

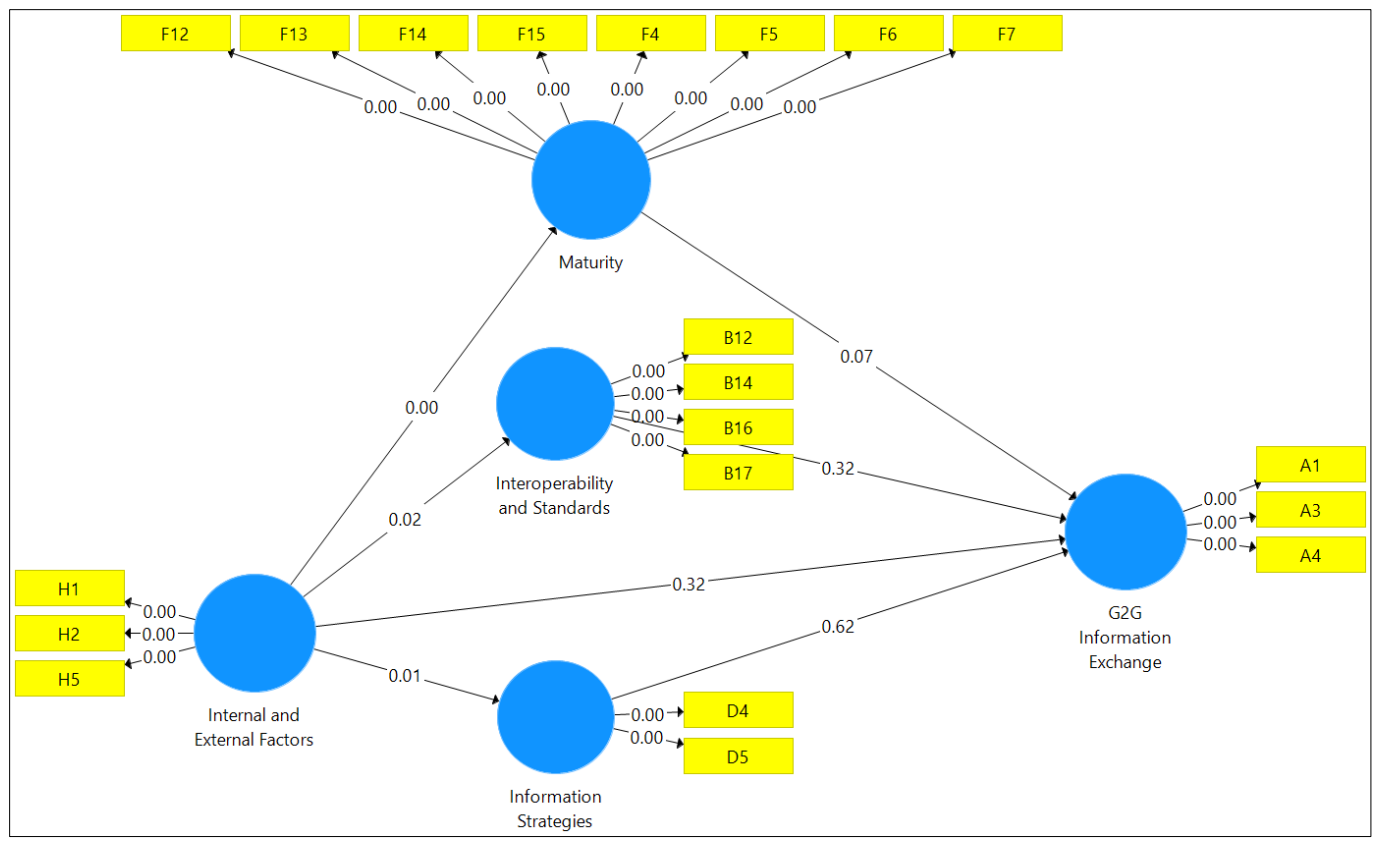

Figure 1. Result of p-values of proposed model

Table 3 shows that the hypothesis $\mathrm{H}_{1}, \mathrm{H}_{4}, \mathrm{H}_{5}, \mathrm{H}_{6}$ were supported, as the multivariate analysis results show in Figure 1. This support is given that p-values less than 0.10. Although Legislation on Electronic Government was associated with organizational maturity, the literature supports the argument that it did not have the same effect on the technological maturity (Coursey \& Norris, 2008). 
Issues in Information Systems

Volume 21, Issue 1, pp. 98-104, 2020

Table 3. Test Results

\begin{tabular}{|c|c|l|}
\hline Hypothesis & P-value results & \multicolumn{1}{|c|}{ Significance } \\
\hline $\mathrm{H}_{1}$ & 0.07 & Supported $(\mathrm{p}<0.10)$ \\
\hline $\mathrm{H}_{2}$ & 0.32 & No Supported $(\mathrm{p}>0.10)$ \\
\hline $\mathrm{H}_{3}$ & 0.62 & No Supported $(\mathrm{p}>.10)$ \\
\hline $\mathrm{H}_{4}$ & 0.00 & Supported $(\mathrm{p}<0.01)$ \\
\hline $\mathrm{H}_{5}$ & 0.02 & Supported $(\mathrm{p}<0.05)$ \\
\hline $\mathrm{H}_{6}$ & 0.01 & Supported $(\mathrm{p}<.05)$ \\
\hline $\mathrm{H}_{7}$ & 0.32 & Not Supported $(\mathrm{p}>0.10)$ \\
\hline
\end{tabular}

\section{CONCLUSIONS}

The results of this study showed that the internal and external factors such as organizational, economic, and political influences, legislative, and technical; and private procedures and interagency agreements are not related to the exchange of information. There is association in the collaboration of two or more agencies, and the potential to increase productivity and efficiency of government operations. However, when the internal and external factors were related to strategies, they did not generate a direct connection with the exchange of information. When the internal and external factors were related to maturity; on aspects of good planning, active participation of human resources and the effective application of technology, they generated a direct connection with the exchange of information. This model explains the existence of three composite relationships where information exchange occurs, and in turn, justifies the efficiency of e-government. Of these, the constructs that were supported in the consolidated model, are limited to organizational maturity on the exchange of information and influence internal and external factors on organizational maturity and information strategies. In a scenario where change is a constant, e-government faces the challenge of dealing with the technological trends on which to build the resources to enable the exchange, integration, dissemination, and effective use of multiple data sources.

\section{REFERENCES}

Al-Hujran, O. \& Al-Dalahmeh, M. (2011). The Role of National Culture on Citizen Adoption of eGovernment web sites. Electronic Journal of e-Government 9(2), 93-106.

Al-Khanjari, Z., Alanee, A., Kraiem, N., \& Jamoussi, Y. (2014). Proposing Real Time Intrusion Detection System Internal Secured Towards a Development of E-Government Web Site. European Scientific Journal, 9(10), 27-37.

Amayah, A. (2013). Determinants of knowledge sharing in a Public Sector organization. Journal of Knowledge Management, 17(3), 454-471

Apostolou, D., Mentzas, G. Stojanovic, L., Thoenssen, B., Pariente, T. (2011). A collaborative decision framework for managing Changes in e-Government services. Government Information Quarterly, 28(1), 101-116.

Asogwa, B. (2013). Electronic government as a paradigm shift for efficient public services: Opportunities and challenges for Nigerian government. Library Hi Tech, 31(1), 141-159.

Bigdeli, Z., Kamal, M., \& de Cesare, S. (2013). Through information sharing inter-Organizational systems in local government. Transforming Government: People, Process and Policy, 7(2), 148-176.

Boulesnane, S., \& Bouzidi, L. (2013). The mediating role of Information Technology in the decision-making context. Journal of Enterprise Information Management, 26(4), 387-399.

Cheng, X., Nolan, T., \& Macaulay, L. (2013). Do not give up the community-A viewpoint of trust development in online collaboration. Information Technology, \& People, 26(3), 298-318.

Cordelia, A., \& Iannacci, F. (2010). Information systems in the public sector the e-Government framework enactment. The Journal of Strategic Information Systems, 19(1), 52-66.

Córdoba-Pachon, J. (2009). to the appropriation of Electronic Government: A Look systemic critique. State, government, public management. Chilean Journal of Public Administration, (14), 60-81.

Córdoba-Pachon, J., \& Orr, K. (2009). Three patterns to Understand e-government: the case of Colombia. International Journal of Public Sector Management, 22(6), 532-554. 


\section{Issues in Information Systems}

Volume 21, Issue 1, pp. 98-104, 2020

Coursey, D., \& Norris, D. F. (2008). Models of e-government: Are they correct? An empirical assessment. Public Administration Review, 68(3), 523-536.

da Silva, F. (2009). Interoperability, Electronic Government and Electronic Governance in Latin America: Expectations and Results. Laboratory of Interactivity and Digital Entertainment Technology, University of Sao Paulo 1-11.

Das, R. K., \& Patra, M. R. (2013). A SERVICE ORIENTED DESIGN APPROACH FOR E-GOVERNANCE SYSTEMS. International Journal of Information Technology Convergence \& Services, 3(3): 1-11.

Di Natale, M., Cucinotta, T., \& Kolachalam, S. (2003). A Modular Architecture for Open-source ICT Services in the Public Administration. In Electronic Government, 167-172.

Fan, J., Zhang, P., \& Yen, D. C. (2014). Among G2G information sharing government agencies. Information, \& Management, 51(1), 120-128.

Fillotrani, P., \& Estévez, E. (2010). Information Sharing for e-Government: Models of information sharing in government. Center for Electronic Governance, United Nations University - International Institute for Software Technology, 1-63.

Flak, LS, Nordheim, S., \& Munkvold, BE (2008). Analyzing stakeholder diversity in G2G Efforts: Combining descriptive stakeholder theory and dialectic process theory. E-Service Journal, 6(2), 3-23.

Gatautis, R., \& Vitkauskaite, E. (2010). Towards eGovernment Interoperability: Lithuania Case. Journal of IBIMA Business Review, 3, 27-35.

Gottschalk, P. (2009). Maturity levels for interoperability in digital government. Government Information Quarterly, 26(1), 75-81.

Haque, S., \& Memon, R.A. (2013). E-Government using Grid Technology: Developing a framework for G2G Grid E-Communication and Collaboration System. International Journal of Research and Independent Studies IJIRS, 2(1), 8-15.

Headayetullah, M., \& Pradhan, G. K. (2010). Interoperability, Information Sharing Protocol Based Trust and Security: Key Issues Digital Government. International Journal of Computer Science, \& Information Technology, 2(3), 72-91.

Jaeger, P. T., \& Bertot, J. C. (2010). Transparency and technological change: Ensuring equal and sustained public access to government information. Government Information Quarterly, 27(4), 371-376.

Kawtrakul, A., Mulasastra, I., Khampachua, T., \& Ruengittinun, S., (2011). The challenges of accelerating connected government and beyond: Thailand perspectives. Electronic Journal of e-Government, 9(2), 183202.

Mendes, K., Cenci, K., \& Fillotrani, P. (2011). Information sharing to e-government. In XIII Workshop of Researchers in Computer Science 1-4.

United Nations. (2012). UN Study on Electronic Government. Department of Economic and Social Affairs, 1-196.

Peled, A. (2011). When collide transparency and collaboration: The USA open data program. Journal of the American Society for Information Science and Technology, 62(11) 2085-2094.

Rahman, H. (2010). Framework of E-governance at the Local Government Level. In Comparative E-Government, Chapter 2, 23-47.

Ruhode, E. (2013). E-government implementation for inter-Organizational information sharing: a holistic approach information system for developing countries, (Doctoral dissertation). Cape Peninsula University of Technology, Cape Town.

Sandoval, R., \& Garcia, J. R. (2011). Evaluation of Electronic Government, Openness and Transparency in Central America. Regional Dialogue on the Information Society, 1-61.

Sheridan, J., \& Tennison, J. (2010). Linking UK Government Data. In Linked Data on the Web (LDOW) http://events.linkeddata.org/ldow2010/papers/ldow2010_paper14.pdf

Shrikant, G. (2012). Study the management and governance of G2G on effective delivery of services. Shodh Gangotri: Repository of Indian Research in Progress 1-6.

Siau, K., \& Long, Y. (2009). Factors Impacting E-government Development. Journal of Computer Information Systems, 50(1). 98-107.

Tripathi, R., Gupta, M., \& Bhattacharya, J. (2013). Effect of Organizational Factors on Interoperability Adoption for Indian Portals. Transforming Government: People, Process and Policy, 7(3), 1-1.

Zinner, H., \& Rukanova, B. (2010). IT or not to mind. IT. Transforming Government: People, Process and Policy, $5(2), 155-166$. 